\title{
PSYCHOPHYSIOLOGY OF SPACEFLIGHT AND AVIATION
}

\author{
Patricia S. COWINGS \\ NASA Ames Research Center, Moffett Field, CA, United States
}

Source of support: Own sources

Author's address: P. Cowings, NASA Ames Research Center, Moffett Field, CA, e-mail: patricia.s.cowings@nasa.gov

Background: In space, the absence of gravity alone causes unique physiological stress. Significant biomedical changes, across multiple organ systems, such as body fluid redistribution, diminished musculoskeletal strength, changes in cardiac function and sensorimotor control have been reported. The time course of development of these disorders and severity of symptoms experienced by individuals varies widely. Space motion sickness (SMS) is an example of maladaptation to microgravity, which occurs early in the mission and can have profound effects on physical health and crew performance. Disturbances in sleep quality, perception, emotional equilibrium and mood have also been reported, with impact to health and performance varying widely across individuals. And lastly, post-flight orthostatic intolerance, low blood pressure experienced after returning to Earth, is also of serious concern. Both the Russian and American space programs have a varied list of human errors and mistakes, which adversely impacted mission goals. Continued probability of human exposure to microgravity for extended time periods provides a rationale for the study of the effects of stress. The primary focus of this research group is directed toward examining individual differences in: (a) prediction of susceptibility to these disorders, (b) assessment of symptom severity, (c) evaluation of the effectiveness of countermeasures, and (d) developing and testing a physiological training method, Autogenic-Feedback Training Exercise (AFTE) as a countermeasure with multiple applications [1]. The present paper reports on the results of a series of human flight experiments with AFTE aboard the Space Shuttle and Mir Space Station, and during emergency flight scenarios on Earth.

Keywords: aerospace medicine, countermeasures, feedback, human performance, manned space flight, microgravity, motion sickness, physiological effects, physiology, psychophysiology

Figures: 8 - Tables: 2 • References: 6 • Full-text PDF: http://www.pjamp.com • Copyright (C 2013 Polish Aviation Medicine Society, ul. Krasińskiego 54/56, 01-755 Warsaw, license WIML • Indexation: Index Copernicus, Polish Ministry of Science and Higher Education 


\section{INTRODUCTION}

The primary objective of our ongoing research program is to develop a behavioral method for facilitating adaptation to space and readaptation to Earth. This method, Autogenic Feedback Training Exercise (AFTE), is a combination of biofeedback and Autogenic Therapy (AT), which involves training subjects to voluntarily control up to 20 physiological responses in 6 hours. AT was found useful for eliciting autonomic responses via techniques such as imagery, which was used to speed up the elicitation of the correct autonomic response. Then biofeedback was used to reward and increase the strength of that response. When AT is administered by a therapist without biofeedback displays, it can require up to 18 months to become effective, and biofeedback without the guided imagery of AT produces considerable variability in learning ability. AFTE is not simply a relaxation training paradigm, but rather involves "exercising smooth muscle", because subjects are taught to both increase and decrease physiological response levels (e.g., vasoconstriction alternating with vasodilatation of peripheral blood vessels, blood pressure increases and decreases, etc.). Changes in response levels are achieved through alternating imagery of "emotional" stimuli and relaxation, where significant learning is achieved in only 6 hours of training.
AFTE was first tested as a treatment for motion sickness. Because this malady is characterized by disturbances in autonomic nervous system function involving many organ systems to varying degrees across individuals, it was necessary to develop a method for training individuals to simultaneously control multiple responses. The training was tailored for each subject with emphasis placed on those physiological variables that were most responsive to motion sickness stimulation. Results of ground based studies indicate that AFTE is effective for both men and women of different age groups and occupations, the training effects transfer across a variety of motion sickness stimuli, and learned control is retained up to three years. Clinical studies of patients with vestibular or autonomic pathologies have shown that AFTE provides substantial relief from symptoms of nausea and syncope.

Figure 1 shows a list of the 20 physiological responses that subjects are taught to control and a detail of one of the training screens (screen 1, not shown, displays analog waveforms of these parameters) used during these training sessions. With this unique AFTE software, the trainer can choose which displays to provide to subjects. Rotating chair tests were used as the metric for determining the effectiveness of AFTE for symptom suppression. To induce motion sickness symptoms,

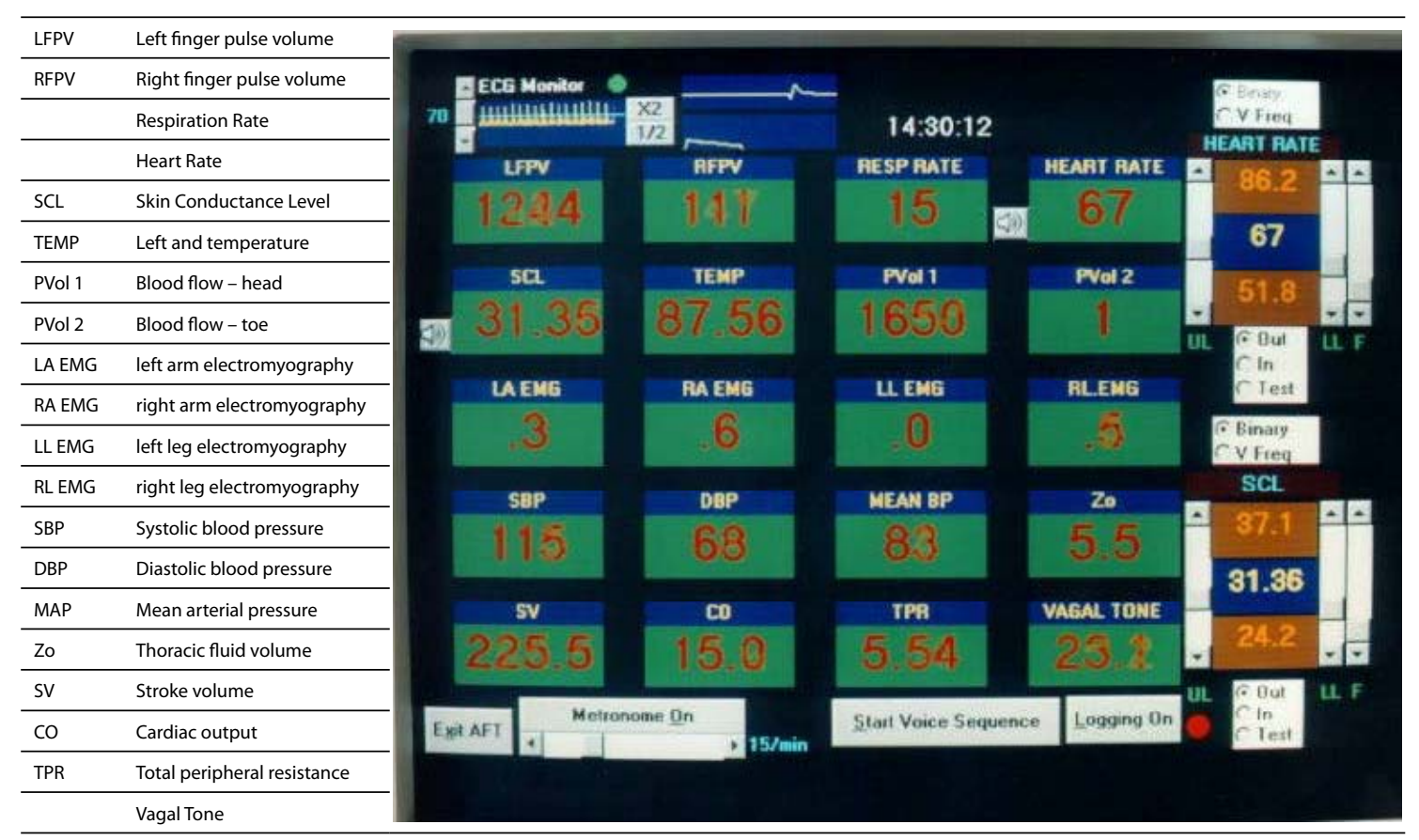

Fig. 1. Left, List of Physiological Responses Used in AFTE, Right Trainer's Console. 

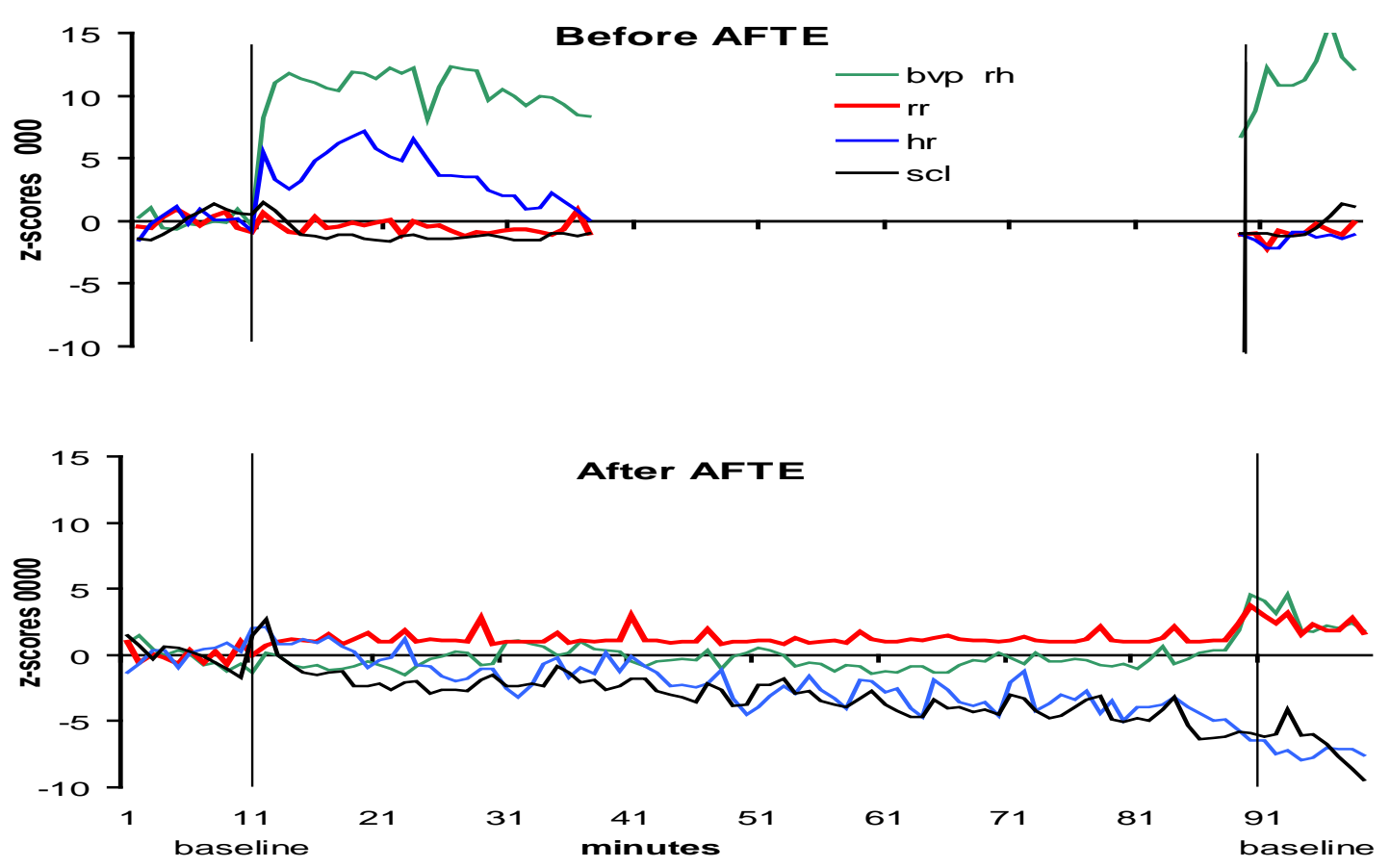

bvp rh=blood flow to right hand, $\mathrm{rr}=$ respiration rate, hr=heart rate, scl=skin conductance

Fig. 2. Physiological Response Profile of a Crewman Before \& After AFTE.

rotation was initiated at $6 \mathrm{rpm}$, and the speed increased in 2 rpm increments at 5 minute intervals. During each 5 minute period, subjects executed 150 head movements (left, right, front and back in random order) at 2 second intervals. After each 5 minute interval at a constant velocity, subjects were asked to report their symptom levels using a standardized diagnostic scale. The test continues until the subject requests a stop, the investigator decides to stop, or until completing 65 minutes of rotation with a top speed of $30 \mathrm{rpm}$. Rotating chair tests are administered (at one week inter- vals) before AFTE and following 2, 4 and 6 hours of training. Successful training is achieved when subjects can: significantly increase the number of rotations tolerated, report fewer (or no) symptoms and show reduced physiological response magnitudes. Figure 2 shows an example of one Shuttle crewmember's physiological response profile before and after training. Responses are normalized (z-scored) so that all parameters can be shown on the same graph. A mean and standard deviation are calculated on a 10 minute pre-test baseline (setting means to zero and changes from baseline

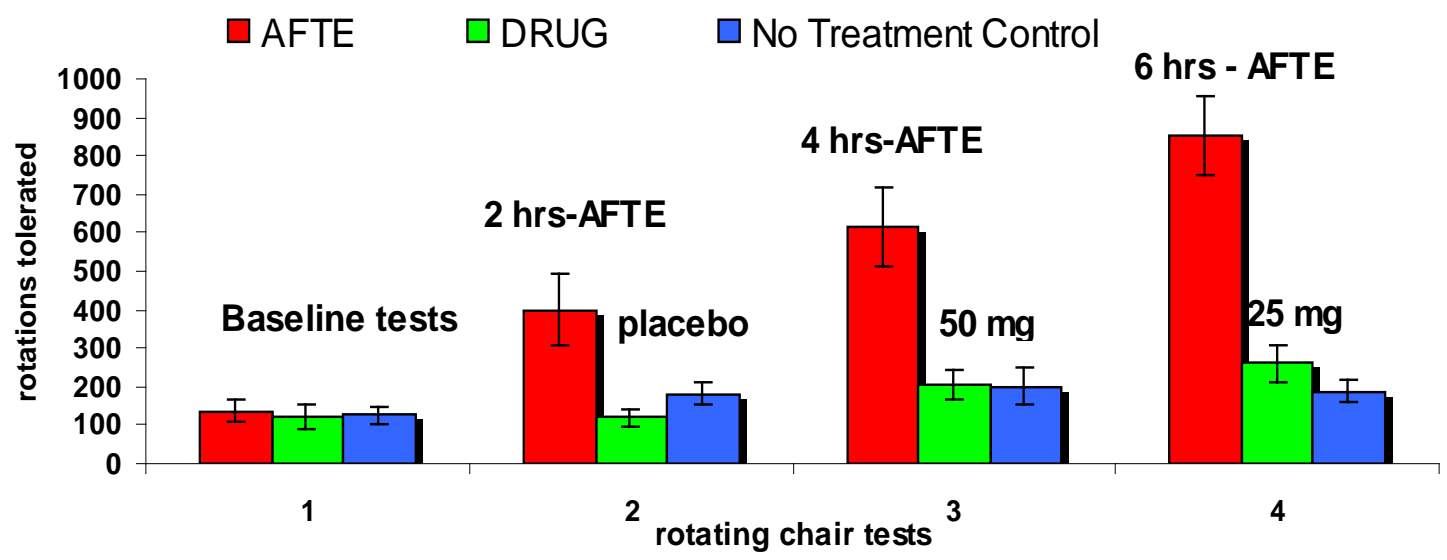

Fig. 3. Changes in Motion Sickness Tolerance ( $\mathrm{N}=12$ per group). 
are in standard deviations. Following training, this subject was able to completely suppress his symptoms and maintain his responses near (or below) his pretest baseline.

Figure 3 shows improved motion sickness tolerance of 3 groups of test participants, matched for gender, age, and initial susceptibility to motion sickness. AFTE is significantly more effective $(p<0.001)$ than the anti-motion sickness medication promethazine or a control group $[3,4]$.

\section{SPACE SHUTTLE MISSIONS}

Data were collected on 6 crewmembers during two separate shuttle flights ( 3 treatment and 3 controls). Of the three crewmembers given AFTE (no medications), two were symptom-free while one experienced only one minor symptom episode on the third mission day. Of the three control group subjects, however, who took a variety of anti-nausea medications, two experienced multiple vomiting episodes, the first occurring within 10-minutes of orbit insertion. For these crewmembers, severe to moderate symptoms persisted over 4 mission days while the third control subject experienced only minor symptoms on the first day in space. Although additional data from space is necessary to validate this countermeasure, these findings suggest that AFTE might be a successful countermeasure for space motion sickness. Figure 4 shows the ambulatory monitoring system used in space aboard both Space Shuttle and Mir Missions.

\section{MIR SPACE STATION MISSIONS}

A study aboard the MIR space station was designed to study individual characteristics of adaptation (i.e., autonomic responses) to long duration spaceflight and possibilities of their correction using an AFTE $[5,6]$. The specific objectives of this study were:

- To determine if the degree of learned autonomic control demonstrated preflight would be retained during 6 months in space.

- Would AFTE improve post-flight orthostatic intolerance of subjects who demonstrated learned control?

Two male cosmonauts were given 6 hours of preflight AFTE and tested for orthostatic tolerance on a tilt table (supine, head-up, and head down tilt (Fig. 5). Inflight, crewmembers were required to participate in 8-days of ambulatory monitoring (AFS-2) at 30-day intervals. Each of these flight days included:

- three 15-minute AFTE sessions,

- cognitive and psychomotor tasks,

- vestibular perception tests and PC-based selfreports of mood states, sleep and symptoms.

\section{RESULTS}

Figure 6 shows Subject 1 physiological responses during his final AFTE session. As can be seen, this subject had learned significant and reliable control of multiple responses with mean arterial pressure changes up to $25 \mathrm{mmHg}$. During the 6-month flight his control of autonomic responses
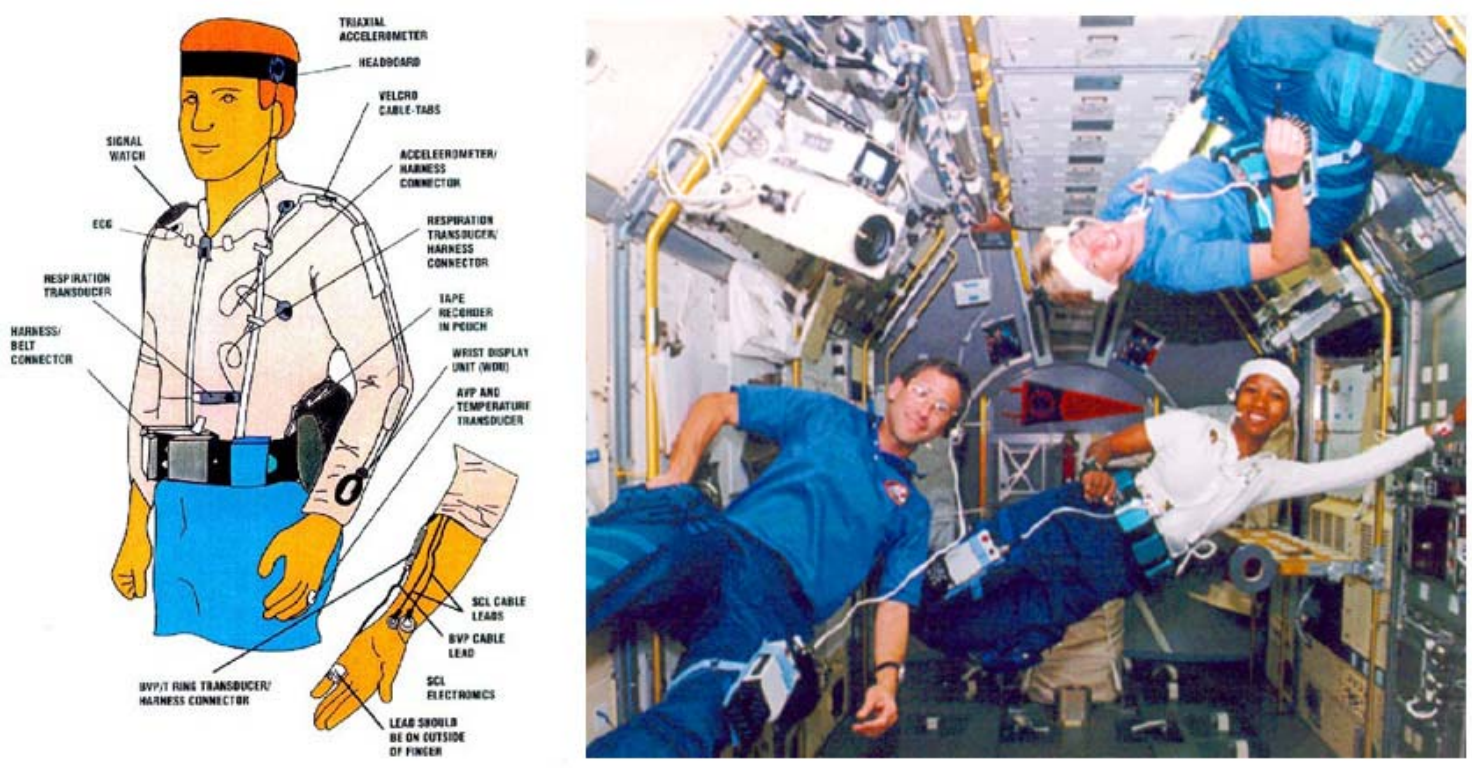

Fig. 4. AFS-2, Ambulatory Monitoring System as Worn Aboard Shuttle. 

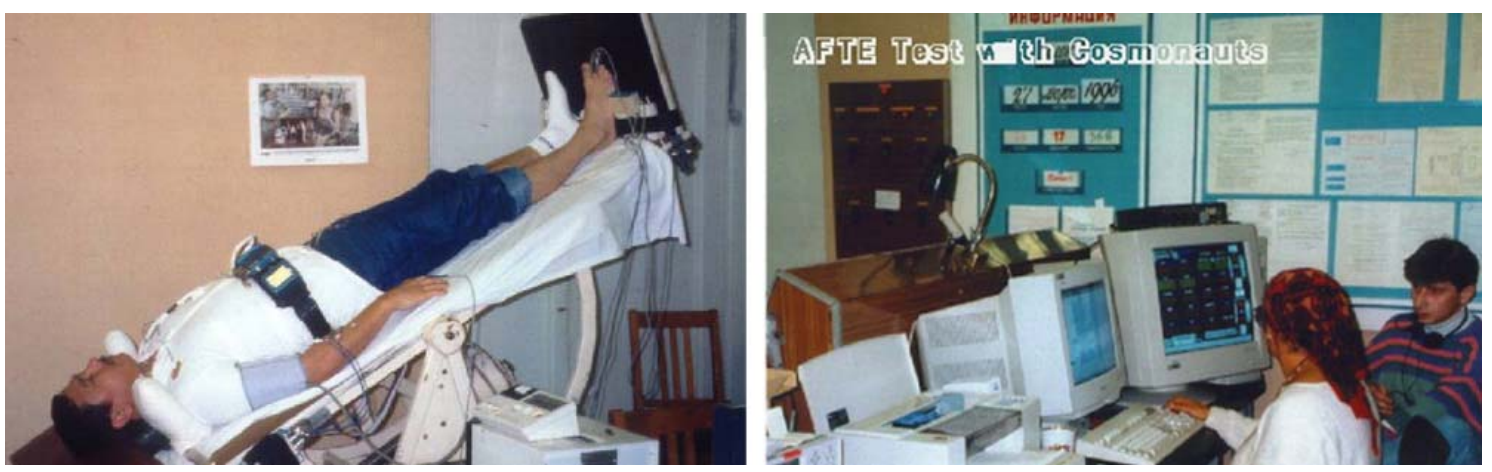

Fig. 5. Cosmonaut during Tilt-table Test AFTE delivered with simultaneous translation.
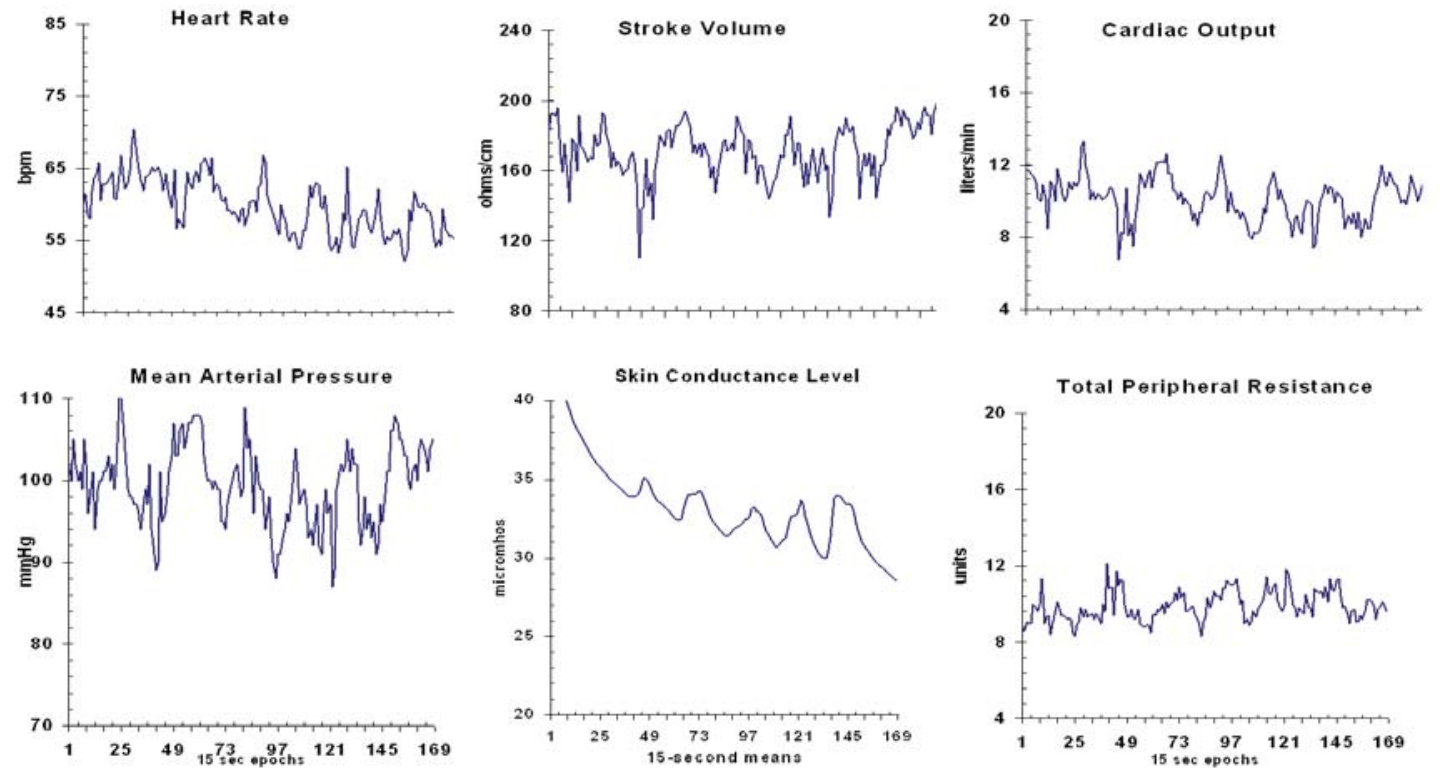

Fig. 6. Subject 1, Final Preflight AFTE Session.
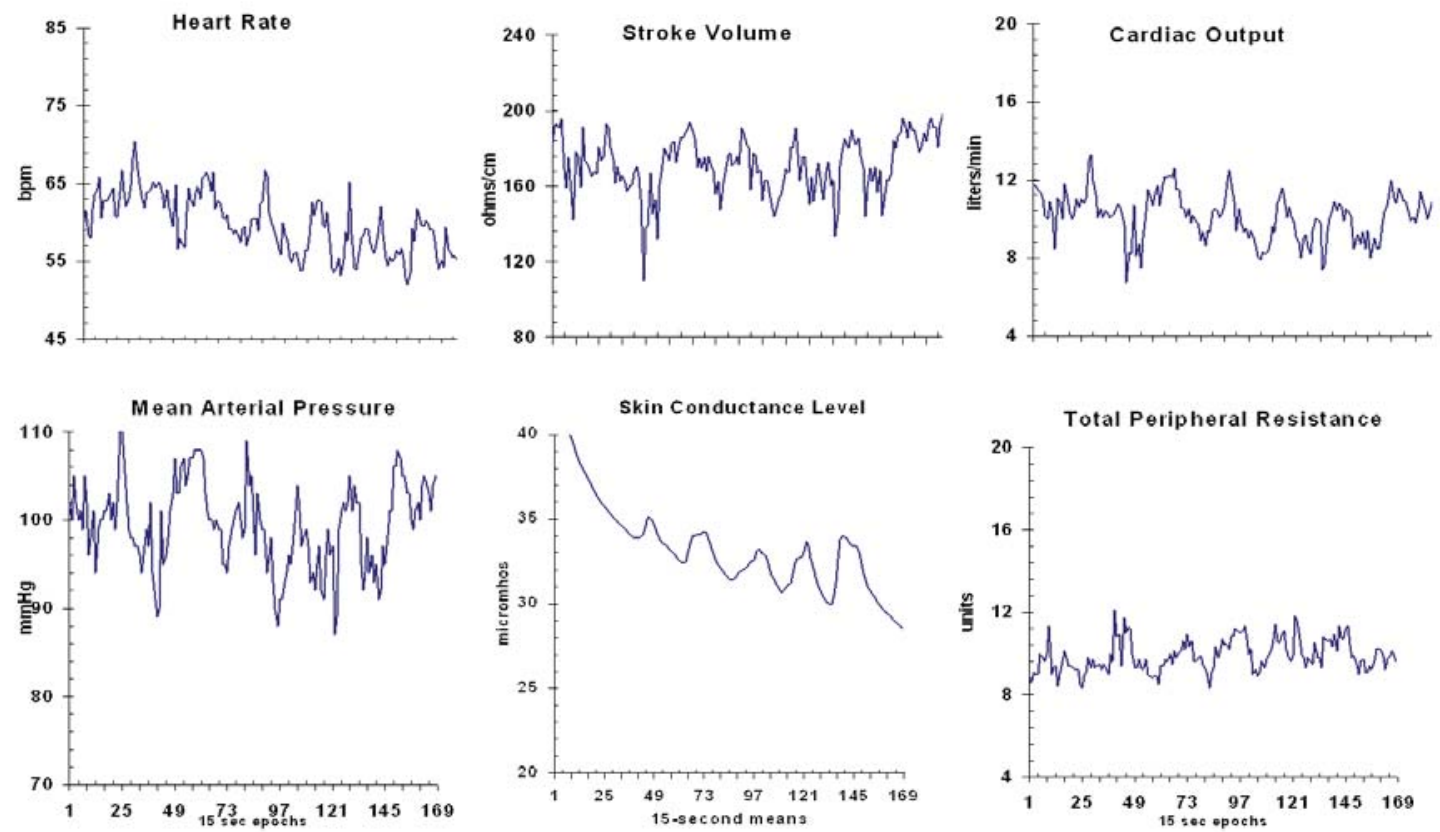

Fig. 7. Subject 2, Final Preflight AFTE Session. 
was similar to his preflight control levels. Subject 2 , however, had more limited control as can be seen by the relatively small changes in response magnitudes across trials (Fig. 7). During the mission, subject 1 performed all of the required inflight practice and monitoring sessions, while subject 2 did not begin AFTE practice until more than 120 days into the mision. Treatment effectiveness for post-flight orthostatic tolerance was evaluated 7-hrs after landing.

Following 208-days in space subject 1 exhibited improved post-flight orthostatic tolerance (while standing erect) compared to his previous 125 day flight, with heart rate $22 \%$ higher, a $50 \%$ increase in arterial tone and a $13 \%$ increase in blood pressure compared to preflight baseline tests. He walked away from the landing site, showing no signs of orthostatic intolerance. Subject 2 experienced pre-syncope within 15 minutes of standing erect. Results suggest that subject 2 might have been better protected if he had additional training and practice sessions both pre- and in-flight.

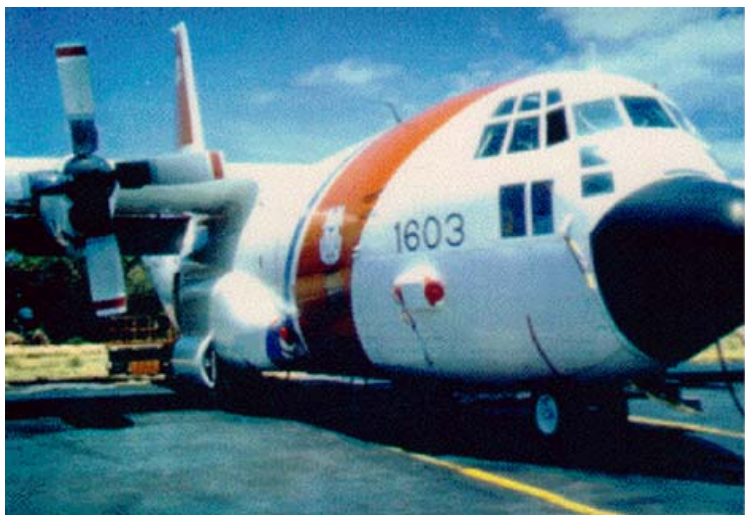

HC-130 aircraft

\section{SEARCH AND RESCUE MISSIONS}

Research continues into applications of this technology to commercial and military aviation. A collaboration between NASA, U.S. Army and Coast Guard examined the effect of AFTE on search and rescue pilots flying under emergency conditions [2]. The objective was to evaluate the effects of training in physiological self-recognition and regulation on crew cockpit performance. The problems to be addressed were: Sustained Operations where fatigue, vigilance, sleep loss, contribute to human error accidents; and Autonomous Mode Behavior, a condition when a high state of physiological arousal is accompanied by a narrowing of the focus of attention. Participants were 17 pilots. Eight were given AFTE (4 HC-130, and $4 \mathrm{HH}-65$ ) and 9 served as controls ( $3 \mathrm{HC}-130$ and $6 \mathrm{HH}-65$, Figure 8). Before training, all pilots participated in a simulated emergency scenario (described below for the two aircraft). Then the AFTE group was given twelve 30-minute daily sessions, followed by a post-training flight. Instructor pilots (IP) provided instructions (simulated emergencies) to each pilot and rated them using a scale developed by

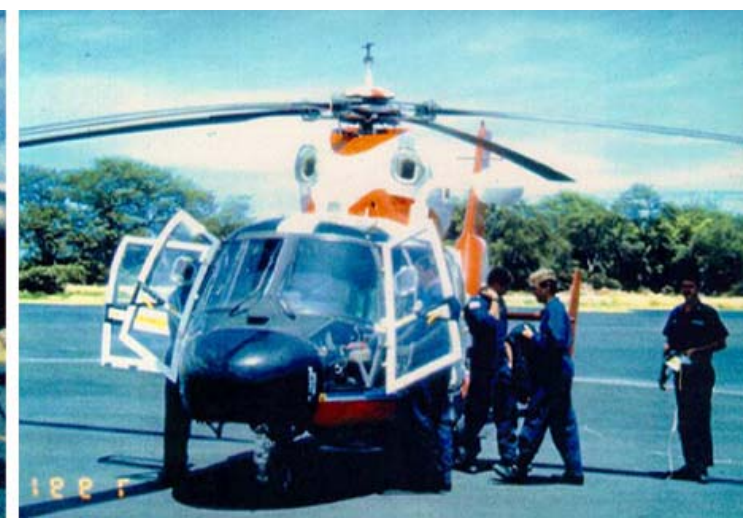

HH-65 Helicopter

Fig. 8. U.S. Coast Guard Search and Rescue Aircraft.

Tab. 1. Flight 2 (post-training) group comparisons: AFTE vs. Control * $\mathrm{p}<0.05$.

\begin{tabular}{|c|c|c|c|c|}
\hline \multirow[b]{2}{*}{ Phases of Flight } & \multicolumn{4}{|c|}{ Performance Dimensions } \\
\hline & Crew Coordination \& Communication & Planning \& Situational Awareness & Stress Management & Aircraft Handling \\
\hline Checklist execution & * & & & \\
\hline Taxi/Takeoff & * & * & & \\
\hline \multicolumn{5}{|l|}{ Initial Cruise } \\
\hline Touch \& Go & & * & * & \\
\hline Cruise Search \& Rescue & & & & + \\
\hline Emergency Initiation & * & & * & \\
\hline Emergency Return to Base & & & * & \\
\hline Emergency Approach and landing & & & * & \\
\hline
\end{tabular}

Note: Flight 1 (pre-training) group comparisons were not significant except a higher score for Controls (+) on cruise search and rescue. 
P. Cowings - Psychophysiology...

Tab. 2. Flight 1 (pre-training) vs. Flight 2 (post-training): AFTE ${ }^{*} \mathrm{p}<0.05$

\begin{tabular}{lccc}
\hline Phases of Flight & Crew Coordination \& Communication & Planning \& Situational Awareness & Stress Management \\
\hline Checklist execution & $*$ & & \\
\hline Taxi/Takeoff & & & \\
\hline Initial Cruise & + & $*$ & $*$ \\
\hline Touch \& Go & $*$ & $*$ & $*$ \\
\hline Cruise Search \& Rescue & $*$ & $*$ & $*$ \\
\hline Emergency Initiation & & $*$ & $*$ \\
\hline Emergency Return to Base & $*$ & $*$ \\
\hline Emergency Approach and landing & $*$ & $*$ \\
\hline
\end{tabular}

Note: flight 1 vs. flight 2 for Controls were not significant, except a lower score for touch and go (+) on flight 2.

the Federal Aviation Authority (FAA). The IP's were not told group assignment of individual pilots, and rated the same individual on both flights.

\section{Simulated Emergency Flight Scenario:}

- Engine 1 fire during touch and go

- Search and Rescue case (downed A-4 pilot 20 miles offshore)

- Engine 2 failure at 200 feet AGL

- Airframe damage, minor fuel leak

- AC bus failure, engine 1 fire

\section{Simulated Emergency Flight Scenario:}

- Simulated engine stall at take off

- Search and Rescue case (distressed boat withinjured crew)

- AC bus failure with loss of gyro, pitch and roll

- Servo-jam warning

- Hydraulic failure at 50 feet AGL

- Landing gear malfunction

\section{RESULTS}

Table 1 shows that during the post-training flights, AFTE subjects performed significantly better than controls in three of four performance dimensions: crew coordination and communication, planning and situational awareness, and stress management. Table 2 compares pre- and post- training performance of the AFTE group only. These subjects significantly improved on all performance dimensions.

These studies indicate that AFTE improves overall performance and execution of duties, improves crew coordination and communication (including: crew briefings, workload delegation, planning, overall technical proficiency). AFTE appears to reduce physiological reactivity to stress, and may aid in successful use and expansion of cockpit resource management training.

In conclusion, AFTE may be a valuable countermeasure for multiple spaceflight related biomedical and performance problems. Additional data from space and ground-based operational tests are needed to validate its effectiveness. Future planned collaborations include transfer NASA AFTE technology and validation studies: training of Polish military pilots; training of U.S. military pilots for airsickness mitigation; training of U.S. veterans as a treatment for Post-Traumatic Stress Syndrome (PTSD) and training of astronauts and cosmonauts in preparing for long duration missions with autonomous crew. To complete these goals, we will use these studies to develop and test new monitoring and training capabilities.

This article was originally published in the Proceedings of the International Workshop on the Psychophysiological Aspects of Flight Safety in Aerospace Operation, 16-17 Sept 2011, Poland.

\section{AUTHORS' DECLARATION:}

Study Design: Patricia S. Cowings; Data Collection: Patricia S. Cowings; Manuscript Preparation: Patricia S. Cowings; Funds Collection: Patricia S. Cowings. The Author declares that there is no conflict of interest. 


\section{REFERENCES}

1. Cowings, P.S. (1990) Autogenic-Feedback Training: A Treatment for Motion and Space Sickness. Chapter 17 in: G. H. Cramptom (Ed.). Motion and Space Sickness. (353-72) CRC Press: Boca Raton, Florida.

2. Cowings, P.S., Keller, M.A., Folen, R.A., Toscano, W.B., Burge, J.D. (2001) Autogenic feedback training and pilot performance: enhanced functioning under search and rescue flying conditions. International Journal of Aviation Psychology. 11(3). 305-15.

3. Cowings, P.S., Toscano W.B. (2000) Autogenic feedback training exercise is superior to promethazine for the treatment of motion sickness. Journal of Clincal Pharmacology. 40 (10). 1154-1165.

4. Cowings, P.S., Toscano, W.B., DeRoshia, C., Miller, N.E. (2000) Promethazine as a motion sickness treatment: impact on human performance and mood states. Aviation, Space and Environmental Medicine. 71 (10). 1013-32.

5. Cowings, P.S., Toscano, W.B., Kamiya, J., Miller, N.E., Pickering, T. and Shapiro, D. (1993) Autogenic Feedback Training as a Potential Treatment for Post Flight Orthostatic Intolerance in Aerospace Crews. Journal of Clinical Pharmacology. 3 (6). 599-608.

6. Kornilova, L.N., Cowings. P.S., Toscano, W.B., Arlaschenko, N.I., Korneev, D.Ju., Ponomarenko, A.V., Sagalovitch, S.V., Sarantseva, A.V., and Kozlovskaya, I.B., (1998b) Correction of the parameters of autonomous reactions in the organism of cosmonaut with the method of adaptive biocontrol. Aviaspace \& Ecology Medicine (Russian journal). 34 (3). 66-69.

Cite this article as: Cowings PS: Psychophysiology of Spaceflight and Aviation. Pol J Aviat Med Psychol, 2013; 19(3): 9-16. 